\section{Discussion of "A 1200-year proxy record of hurricanes and fires from the Gulf of Mexico coast..." (Liu et al., 2008)}

Following a recent period (1995-2008) of increased cyclone frequency and intensity (Elsner et al., 1999), the recurrence of severe (Saffir-Simpson Scale Category 3) and "catastrophic" (Categories 4 and 5) Atlantic hurricanes is again in the forefront of public and professional interest. The credibility of evidence (Liu and Fearn, 2000, 2002; Liu et al., 2008) in support of the cyclic character of land-falling catastrophic hurricanes became more than an abstract academic matter. While the restated and expanded claim for 600-yr "superhurricane" cycles, first voiced by Liu and Fearn (1993) did create sensation in the public press and is still being cited in professional publications, the criticism (Otvos, 1999, 2002) of underlying assumptions was all but ignored.

1. Sand layers interlaminated with paralic lacustrine sequences by themselves provide no conclusive proof for extreme overwash across high dune ridges during catastrophic hurricanes. Alternate modes of deposition during lesser storms may well account for their presence. The thickness, number, and distribution area of the interspersed sand layers may depend on the proximity to inlets and shore, on gaps and low saddles in beach ridges, more accessible to overwash, and on the slope configuration of adjacent dune ridge slopes eroded by overtopping waves or surface runoff (Otvos, 1999, 2002; Lambert et al., 2003).

Sand also enters enclosed coastal lakes and estuaries through preexisting and newly formed inlets during lesser storms and may have been transported over very short distances by traction and/or suspension currents across Lake Shelby's flat bottom from the shallow, wide sandy bottom perimeter to its sapropel-floored center. Phytoliths, another proposed evidence for hurricanes (Lu and Liu, 2005; Liu et al., 2008), may have been eroded from dune soils by common surface processes as well. Conversely, absence of sand laminae from lake muds does not disprove major hurricane strikes (Lambert et al., 2003, 2008).

2. Liu's assumption of the 600-yr superhurricane recurrence during a recent 3200-yr "hyperactive" phase, following prolonged calm, was not based primarily on lake deposits but on sand layers dated $4760-2650{ }^{14} \mathrm{C}$ yr BP (Liu and Fearn, 1993). Sand layers are interspersed with estuarine clay that fills a late Pleistocene incised valley beneath lacustrine sands and muds. In continuous interchange with the nearshore Gulf, sand transport to estuaries is not limited to major hurricanes, let alone catastrophic ones. Minor storms that also carry coarser sediment into estuaries.

Representing significant depositional regression in SE Alabama and NW Florida, an extensive late Holocene strandplain complex prograded over transgressive nearshore and estuarine deposits (Otvos, 1999, 2005, p. 145-153). After separation of the developing Lake Shelby basin from the Gulf, a thin sapropel (gyttja) interval has been accumulating in its interior for the last $800 \mathrm{yr}$ (Lambert et al., 2003, 2008).
3. Introducing major errors, the published raw dates of estuarine and lacustrine sand layers, supposed evidence for cyclicity, were uncorrected for sapropel TOC and marine and lacustrine shells. While a sand layer in Lake Shelby's sapropel unit dated AD 1250 (Liu and Fearn, 1993), subsequent reservoir correction conclusively linked it to the AD 1717 hurricane (Lambert et al., 2003, 2008). New raw dates 1250-920 ${ }^{14} \mathrm{C}$ yr BP of sand layers from the sapropel of adjacent Little Lake (Liu et al., 2008) also fail to document cyclicity. Corrected, they should conform with the accurate age of Lake Shelby's sapropel unit.

4. $\mathrm{C}$ and $\mathrm{N}$ isotope signatures in fine organic matter of paralic lakes (Lambert et al., 2003, 2008) are much better indicators of the current velocity and duration of storm-driven, fertilizing sea waters than are sand laminae. Due to its sensitivity and because most hurricane storm inundations did not leave sand laminae in Lake Shelby's sapropel (gyttja) interval, this method represents a highly significant new research tool. The three largest isotope peaks, ca. $180 \mathrm{yr}$ apart, represent the greatest hurricane impact on the lake's hydrochemical and hydrodynamic regime. Based on "isolated" vs "flooded" lake states, the authors also sought to correlate isotope data with extreme hurricanes. The ephemeral impact of Category 3 Hurricane Ivan (2004) on the hydrology (Lambert et al., 2008), sediments, and sediment chemistry of Lake Shelby near the landfall site suggests that a hurricane's rotational velocity alone does not determine the extent and duration of this geochemical shift.

Lambert et al. (2008, Figure 9) recognized signatures of 11 hurricanes in the Lake Shelby sapropel interval. Designations "severe" and "catastrophic," used interchangeably, were associated with isotope peaks at or above the 2 sigma threshold. Failing to attain this value, five highly destructive Alabama cyclones of the 20th century are absent from this plot. Discernable in Figure 7 of Lambert et al. (2008), these include the 1906 hurricane and Category 3 hurricanes of AD 1916 (July and October), 1926, and 1979 (Frederic). Among the eleven hurricanes designated as "severe," Baker (AD 1950) at $175 \mathrm{~km} / \mathrm{h}$ belonged to only high-Category 2 , reduced to Category 1 at landfall. Cyclones of lower rotational velocities apparently may produce significant isotope shifts in converting fresh water lakes to "flooded" (fertilized) mode. Slower forward speed, accompanied by lesser rainfall would lead to more thorough and prolonged lake water replacement by salt water. Focusing by the offshore and nearshore bottom topography as during Hurricanes Camille (AD 1969) and Katrina (AD 2005), both Category 3 cyclones at landfall and associated with by far the most extensive documented inundation of the coastal region by saline marine waters even during lower category hurricane strikes. Further complicating the recognition of differences between hurricane categories are the identical sedimentary and geochemical signatures of lower category cyclones near landfall and those of major and catastrophic hurricanes of more distant landfall sites. Georges' 3.6-4.2 m record flood levels east of its landfall (Otvos, 2004b) compare with the 4.3-m high of Ivan, Category 3 at landfall. A nearby landfall by Category 2 Hurricane Georges would have overtopped beach ridges around Lake Shelby. Correlation with sediment signatures prior to the 1900s is hampered 
by the absence of sufficiently detailed data on hurricane velocities and duration.

Clearly, the making of direct correlations between the presently utilized five hurricane categories and various complex sedimentary, geomorphic, geochemical, hydrological factors and signatures are fraught with uncertainties, inconsistencies, and other complications. 5. The suggested correlation between catastrophic hurricanes and lightning fires is reasonable. However, frequent prehistoric forest fires would have rapidly consumed the woody debris soon after major hurricanes strikes, not decades later. Of the four major Little Lake charcoal peaks of Liu et al. (2008), only the oldest two correlate well with a sand layer, but without evidence for the "catastrophic" level of the hurricanes and the forest destruction (Figures 2-4). The third, correlated with higher dinoflagellate content but lacking sand laminae, reflects salt water invasion, not necessarily by a major hurricane. Wind and interception by rain may also concentrate pollen in lake deposits. Instead of forest destruction-related pine pollen lows, pollen highs mark the 1968 fire and two of the three natural fires and organic decomposition. Katrina (2005), “only" mid-Category 3 at landfall, drove catastrophic forest devastation and a record 8-12 m storm surge (Otvos and Carter, 2008).

6. The term "Pamlico Barrier," applied to the Pleistocene ridge north of the paralic lakes (Liu et al., 2008, p. 31 and Figure 1), is obsolete and a misnomer. The lower interval in the ridge represents the Sangamon Interglacial Gulfport coastal barrier, buried under Wisconsin stage sand dunes and eolian sand sheet (Otvos, 2004a).

\section{References}

Elsner, J.B., Kara, A.B., Owens, M.A., 1999. Fluctuations in North American hurricane frequency. Journal of Climate 12, 427-437.

Lambert, W.J., Aharon, P., Rodriguez, A.V., 2003. An assessment of the late Holocene record of severe storm impacts from Lake Shelby, Alabama. Gulf Coast Association of Geological Societies Transactions 53, 443-452.
Lambert, W.J., Aharon, P., Rodriguez, A.V., 2008. Catastrophic hurricane history revealed by organic geochemical proxies in coastal lake sediments: a case study of Lake Shelby, Alabama (USA). Journal of Paleolimnology 39, 117-131.

Liu, K.-b., Fearn, M.L., 1993. Lake sediment record of late Holocene hurricane activities from coastal Alabama. Geology 21, 793-796.

Liu, K.-b., Fearn, M.L., 2000. Reconstruction of prehistoric landfall frequencies of catastrophic hurricanes in NW Florida from lake sediment records. Quaternary Research 54, 238-245.

Liu, K.-b., Fearn, M.L., 2002. Lake sediment evidence of coastal geologic evolution and hurricane history from Western Lake, Florida. Reply to Otvos. Quaternary Research 57, 29-431.

Liu, K.-b., Lu, H., Shen, C., 2008. A 1200-year proxy record of hurricanes and fires from the Gulf of Mexico coast: testing the hypothesis of hurricane-fire interactions. Quaternary Research 69, 29-41.

Lu, H.Y., Liu, K.-b., 2005. Phytolith indicators of coastal environmental changes and hurricane overwash deposition. The Holocene 15, 965-972.

Otvos, E.G., 1999. Quaternary coastal history, basin geometry and assumed evidence for hurricane activity, northeastern Gulf of Mexico coastal plain. Journal of Coastal Research 15, 438-443.

Otvos, E.G., 2002. Discussion of "Prehistoric landfall frequencies of catastrophic hurricanes..." (Liu and Fearn, 2000). Quaternary Research 57, 425-428.

Otvos, E.G., 2004a. Prospects of interregional correlations using Wisconsin and Holocene aridity episodes, northern Gulf of Mexico coastal plain. Quaternary Research 61, 105-118.

Otvos, E.G., 2004b. Beach aggradation following hurricane landfall: impact comparisons from two contrasting hurricanes, northern Gulf of Mexico. Journal of Coastal Research 20, 326-339.

Otvos, E.G., 2005. Coastal barriers, Gulf of Mexico: Holocene evolution and chronology. Journal of Coastal Research S1-42, 141-163.

Otvos, E.G., Carter, G.A., 2008. Hurricane degradation-barrier development cycles, northeastern Gulf of Mexico. Landform evolution and island chain history. Journal of Coastal Research 24, 463-478.
Ervin G. Otvos

Department of Coastal Sciences, University of Southern Mississippi, Ocean Springs, Mississippi 39566-7000, USA E-mail address: otvos@cableone.net. 